() Open Access Full Text Article

REVIEW

\title{
Intra-articular corticosteroids in the treatment of juvenile idiopathic arthritis: Safety, efficacy, and features affecting outcome. A comprehensive review of the literature
}

This article was published in the following Dove Press journal:

Open Access Rheumatology Research and Reviews

14 May 2009

Number of times this article has been viewed

\author{
Alisa Carman Gotte \\ University of Texas Southwestern \\ Medical Center, Department \\ of Pediatrics, Dallas, TX, USA
}

Correspondence: Alisa Carman Gotte University of Texas Southwestern Medical Center, Department of Pediatrics,

5323 Harry Hines Boulevard, Dallas, TX 75390-9063, USA

Tel +I 2146482386

Fax +I 2146483557

Email alisa.gotte@utsouthwestern.edu

\begin{abstract}
Intra-articular corticosteroid injection (IACI) has been used in the treatment of inflammatory arthritis in adults for over fifty years. Over the last two decades, IACI has become an important tool in the management of juvenile idiopathic arthritis (JIA), particularly in the oligoarthritis subset of JIA. Many factors may affect the efficacy of this treatment modality, although the majority of evidence on this topic is anecdotal, nonconvincing, or conflicting. The review examines the rationale, efficacy, safety, and application of the use of IACI in the treatment of JIA, focusing on factors that affect the outcome following IACI.
\end{abstract}

Keywords: juvenile idiopathic arthritis, juvenile rheumatoid arthritis, glucocorticoids, treatment, children

\section{Introduction}

Juvenile idiopathic arthritis (JIA) describes a heterogeneous collection of chronic inflammatory conditions which have in common arthritis of unknown etiology, of at least six weeks duration, and with onset before the 16th birthday. More homogeneous categories of JIA have been delineated by the International League of Associations for Rheumatology (ILAR) classification based upon predominant clinical and laboratory features. ${ }^{1}$ Intra-articular corticosteroid injection (IACI) is a frequently used therapeutic modality in the management of JIA, particularly in the subset of JIA patients with oligoarthritis, defined by ILAR as arthritis affecting less than five joints during the first six months of disease. The safety and efficacy of IACI to improve pain, mobility, and morning stiffness in adults with rheumatoid arthritis (RA) have been confirmed in a recent systematic review of placebo-controlled randomized trials, ${ }^{2}$ however no such placebo-controlled randomized trials exist in children with JIA. The use of IACI in JIA has been previously reviewed by Dent and Walker, ${ }^{3}$ See,${ }^{4}$ Cleary and colleagues, ${ }^{5}$ and Hashkes and Laxer. ${ }^{6}$ This article serves to expand upon these previous reports and to review the current literature regarding the rationale, efficacy, safety, and application of the use of IACI in the treatment of JIA, focusing on factors that affect the outcome following IACI.

\section{Historical aspects}

The use of IACI for the treatment of inflammatory arthritis in adults was initially reported by Hollander in $1951 .^{7}$ The use of IACI in children was first noted anecdotally 
in $1979,{ }^{8}$ and the first prospective evaluation of IACI in the management of chronic arthritis in children was reported by Allen and colleagues in $1986 .{ }^{9}$ Since that time, IACI has become a common and accepted tool in the management of JIA, with $44 \%$ of children with juvenile rheumatoid arthritis (JRA) receiving IACI as part of the therapy. ${ }^{10}$ IACI use is particularly common in the management of the oligoarthritis subtype of JIA, with only non-steroidal anti-inflammatory drugs (NSAIDs) utilized more frequently. ${ }^{11}$ In a recent survey of the treatment preferences of United States and Canadian pediatric rheumatologists, $90 \%$ of respondents recommended IACI as a treatment strategy for uncomplicated monoarthritis of the knee in oligoarticular JIA, and $27 \%$ of respondents recommended IACI as the initial therapy in this setting. ${ }^{12}$

\section{Rationale for use}

Glucocorticoids have a wide range of anti-inflammatory and immunosuppressive effects, including increased transcription of anti-inflammatory genes; inhibition of expression of multiple inflammatory genes including cytokines, enzymes, receptors, and adhesion molecules; and inhibition of T-lymphocyte activation, proliferation, and survival. ${ }^{13}$ However, the systemic use of glucocorticoids is associated with substantial toxicity, limiting its role in the treatment of chronic disorders such as JIA. Targeting glucocorticoids to the joint greatly reduces these systemic adverse effects while still attaining local anti-inflammatory benefits. ${ }^{14}$ Transient decreases in the serum inflammatory cytokines Interleukin (IL)-2, IL-4, IL-6, IL-7, IL-17, and tumor necrosis factor- $\alpha$ (TNF- $\alpha$ ) have been demonstrated following IACI in a patient with RA, suggesting that local corticosteroid treatment also has systemic effects on key inflammatory regulators. ${ }^{15}$

\section{Indications for IACI}

Pediatric rheumatologists employ IACI to attain various goals. In the management of oligoarthritis, IACIs can be used to resolve synovitis, either as the initial and sole therapy or as a contingency therapy should NSAIDs prove ineffective. ${ }^{12}$ IACIs are also utilized to avoid or decrease systemic therapy, ${ }^{16}$ to prevent or treat leg length discrepancies and joint contractures, ${ }^{16,17}$ to facilitate physical therapy and rehabilitation, ${ }^{18}$ to effect positive changes in gait, ${ }^{19}$ and to relieve pain. Additionally, IACI can have a role in the management of polyarticular disease, either administered as multiple simultaneous IACIs or as IACIs targeted to a few problematic joints, serving as a bridge while disease-modifying antirheumatic (DMARD) therapy becomes effective, as well as treating joint deformities and providing pain relief. ${ }^{4}$

\section{Efficacy}

Direct comparison of studies evaluating the efficacy of IACI in JIA is difficult due to the significant variability that exists in the study design; patient population; type, dose, and frequency of corticosteroid used; outcome measure employed; and length of follow-up reported. More than 15 investigations have been reported in the English language regarding the efficacy of IACI in the treatment of JIA, the vast majority of which are either retrospective chart reviews or open label studies (see Table 1). Only three studies have been reported which employed some form of randomization and blinding, ${ }^{20-22}$ all of which compared various corticosteroid preparations. No comparison exists between a corticosteroid and placebo injection.

\section{Complete resolution of arthritis}

The most stringent primary outcome reported in studies evaluating the efficacy of IACI in JIA is that of complete resolution of all signs and symptoms of inflammation, specifically, joint effusion, heat and tenderness. This was the outcome used by Allen and colleagues in the initial prospective report of the efficacy of IACI, a noncontrolled, nonblinded study of IACI in 49 knees of 40 children with various types of chronic arthritis (including 29 children with pauciarticular JRA, a condition equivalent to oligoarthritis under the current nomenclature scheme) who had failed at least three months of aspirin treatment with or without other NSAIDs. ${ }^{9}$ Complete resolution of signs and symptoms of inflammation occurred in $63.3 \%$ of knees injected with 20 to $40 \mathrm{mg}$ of triamcinolone hexacetonide (TH) at six months post-injection, $45 \%$ of knees at 12 months, and $16.1 \%$ of knees at 24 months.

Slightly better response rates ranging from $67 \%$ to $82 \%$ were found in subsequent studies that also evaluated for complete resolution of arthritis at six months post-IACI. In a retrospective review of 27 knees injected with 10-20 mg triamcinolone acetate (TA) in 21 patients with type 1 pauciarticular juvenile chronic arthritis (JCA), Hertzbergerten Cate and colleagues reported a response rate of $70 \%$ at six months post-injection. ${ }^{23}$ In an open label study, Ravelli and colleagues reported resolution of arthritis at six months in $69 \%$ of 94 children with JIA (including 81 patients with oligoarthritis, either persistent or extended) who had either one or both knees injected with $1 \mathrm{mg} / \mathrm{kg} \mathrm{TH}$, up to $40 \mathrm{mg} .{ }^{24}$ In a smaller open label report of 35 children with oligoarthritis of the knee and two children with enthesitisrelated arthritis of the knee, Lepore and colleagues found 68\% of children injected with $1 \mathrm{mg} / \mathrm{kg}$ TH (maximum $40 \mathrm{mg}$ ) had 
Table I Summary of clinical studies of IACI in JIA

\begin{tabular}{|c|c|c|c|c|c|}
\hline Author, year & $\mathbf{N}$ & Study design & Steroid used & Outcome measures & Results \\
\hline Allen $1986^{\circ}$ & 40 & Open label & TH, 20-40 mg/joint & CCR & $\begin{array}{l}63.3 \% \text { response at } \\
\text { six months }\end{array}$ \\
\hline Balogh $1987^{22}$ & 23 & $\begin{array}{l}\text { Randomized, } \\
\text { double-blinded }\end{array}$ & TH vs BM & $\begin{array}{l}\text { Difference in knee } \\
\text { circumference }\end{array}$ & $\begin{array}{l}\text { TH: }-1.7 \mathrm{~cm} \mathrm{BM:} \\
+\mathrm{I} \mathrm{cm}\end{array}$ \\
\hline Earley $1988^{27}$ & 60 & Open label & $\mathrm{TH}$ & $\begin{array}{l}\text { Reduction in } \\
\text { inflammation }\end{array}$ & $\begin{array}{l}\text { "Excellent" or "good" } \\
\text { response in } 77 \% \text { at } \\
\text { one year }\end{array}$ \\
\hline $\begin{array}{l}\text { Hertzberger-ten Cate } \\
\left.199\right|^{23}\end{array}$ & 21 & $\begin{array}{l}\text { Retrospective } \\
\text { review }\end{array}$ & TA $10-20 \mathrm{mg} /$ joint & CCR & $\begin{array}{l}70 \% \text { response at } \\
\text { six months }\end{array}$ \\
\hline Honkanen $1993^{26}$ & 79 & $\begin{array}{l}\text { Retrospective } \\
\text { review }\end{array}$ & $\begin{array}{l}\text { MP I. } 5 \text { mg/kg vs TH } \\
0.7 \mathrm{mg} / \mathrm{kg}\end{array}$ & $\begin{array}{l}\text { Reduction } \\
\text { in inflammation }\end{array}$ & $\begin{array}{l}75 \% \text { response at } \\
\text { six months }\end{array}$ \\
\hline Padeh $1998^{16}$ & 71 & Open label & TH I0-40 mg/joint & CCR & $\begin{array}{l}82 \% \text { response at } \\
\text { six months }\end{array}$ \\
\hline Sherry $1999^{17}$ & 30 & Open label & $\begin{array}{l}\text { TH } 20 \mathrm{mg} / \text { joint } \\
\text { vs no IACI }\end{array}$ & $\begin{array}{l}\text { LLD, thigh circumference } \\
\text { discrepancy }\end{array}$ & $\begin{array}{l}\mid A C l: \text { no LLD, No IACl: } \\
7 \text { with LLD }\end{array}$ \\
\hline Breit $2000^{28}$ & 194 & $\begin{array}{l}\text { Retrospective } \\
\text { review }\end{array}$ & $\mathrm{TH}$, variable dose & Duration of improvement & $\begin{array}{l}\text { Depends on subgroup } \\
\text { of disease }\end{array}$ \\
\hline Ravelli $200 I^{24}$ & 94 & Open label & $\mathrm{TH}, \mathrm{I} \mathrm{mg} / \mathrm{kg}$ & $\mathrm{CCR}$ & $\begin{array}{l}69 \% \text { response at } \\
\text { six months }\end{array}$ \\
\hline Neidel $2002^{39}$ & 48 & Open label & $\mathrm{TH}, \mathrm{I} \mathrm{mg} / \mathrm{kg}$ & $\begin{array}{l}\mathrm{CCR} \text { and radiographic } \\
\text { remission }\end{array}$ & $\begin{array}{l}76 \% \text { response at } \\
\text { two years }\end{array}$ \\
\hline Lepore $2002^{25}$ & 37 & Open label & $\mathrm{TH}, \mathrm{I} \mathrm{mg} / \mathrm{kg}$ & $\mathrm{CCR}$ & $\begin{array}{l}68 \% \text { response at } \\
\text { six months }\end{array}$ \\
\hline Zulian $2003^{20}$ & 85 & $\begin{array}{l}\text { Randomized by drug } \\
\text { availability }\end{array}$ & $\begin{array}{l}\text { TH, I mg/kg vs TA, } \\
\text { I mg/kg }\end{array}$ & $\begin{array}{l}\text { Decrease in articular } \\
\text { score } \geq 60 \%\end{array}$ & $\begin{array}{l}\text { TH: } 81.4 \% \text { TA: } 53.3 \% \\
\text { response at six months }\end{array}$ \\
\hline Zulian $2004^{21}$ & 37 & $\begin{array}{l}\text { Randomized, } \\
\text { double-blinded }\end{array}$ & $\begin{array}{l}\mathrm{TH}, \mathrm{I} \mathrm{mg} / \mathrm{kg} \text { vs TA, } \\
2 \mathrm{mg} / \mathrm{kg}\end{array}$ & $\begin{array}{l}\text { Decrease in articular } \\
\text { score } \geq 60 \%\end{array}$ & $\begin{array}{l}\text { TH: } 89.7 \% \text { TA: } 61.5 \% \\
\text { response at six months }\end{array}$ \\
\hline Eberhard $2004^{29}$ & 85 & Open label & $\begin{array}{l}\text { TH } 20-40 \mathrm{mg} / \text { joint vs TA } \\
60-80 \mathrm{mg} / \text { joint }\end{array}$ & Time to relapse & $\begin{array}{l}\text { TH: } 10.14 \text { mo TA: } 7.75 \\
\text { mo }\end{array}$ \\
\hline
\end{tabular}

Abbreviations: BM, betamethasone; CCR, complete clinical resolution of arthritis; IACl, intra-articular corticosteroid injection; JIA, juvenile idiopathic arthritis; LLD, leg length discrepancy; MP, methylprednisolone; TA, triamcinolone acetonide; TH, triamcinolone hexacetoide.

disappearance of clinical signs of inflammation of at least six months duration. ${ }^{25}$ The highest rate of complete resolution of joint inflammation was reported by Padeh and Passwell in an open-label, nonrandomized evaluation, who found complete remission at six months post-IACI with $10-40 \mathrm{mg}$ of TH in $82 \%$ of 300 injected joints in 71 children with chronic arthritis (including 43 children with pauciarticular JRA). ${ }^{16}$

\section{Improvement in arthritis}

Additional investigations have evaluated the efficacy of IACI based on improvement in physical signs and symptoms of arthritis without requiring complete resolution of these features. In an early retrospective review of 34 children with JCA injected with $0.7 \mathrm{mg} / \mathrm{kg}$ of TH in a knee (a lower dose than used in other studies), Honkanen and colleagues defined remission in such a way that allowed for minimal signs of inflammation to still be present. ${ }^{26}$ In this study, the more liberal definition of response did not result in significant variation from response rates reported elsewhere, with a remission rate of approximately $75 \%$ at six months from injection and approximately $60 \%$ at 12 months from injection reported. Also using an outcome definition that permitted a mild degree of abnormality to be present yet still be classified as a good response, Earley and colleagues reported higher rates of response in their experience of $83 \mathrm{TH}$ injections to the knee in 60 children with pauciarticular JCA less than 10 years old, finding either an "excellent" (absence of swelling, limitation, or deformity) or "good" (slight swelling or deformity in a well-functioning knee) response in $77 \%$ of knees at one year post-injection. ${ }^{27}$

Further impressive response rates were reported by Zulian and colleagues in $2003^{20}$ and again in $2004,{ }^{21}$ who defined response to treatment as either absence of synovitis or decrease in joint inflammation leading to a reduction of the articular 
score by more than $60 \%$ from baseline. The articular score was obtained by scoring each of four variables (swelling, limitation of range of motion, pain on passive movement, and warmth) on a scale of zero to three (three being most severe), then summing the scores for each variable. In the 2003 report, 42 joints of children with oligoarticular JIA were injected with $1 \mathrm{mg} / \mathrm{kg}$ of $\mathrm{TH}$ (maximum $40 \mathrm{mg}$ ), and response rates of $81.4 \%$ at six months, $67.1 \%$ at 12 months and $60 \%$ at 24 months were reported. Of note, subjects were excluded if they had ongoing chronic disease, radiographic erosions, or had received an IACI in the preceding 12 months, potentially selecting out children with more severe disease and thus introducing a selection bias. In the 2004 report, 37 children with JIA (32 with oligoarthritis, either persistent or extended) who had symmetrical arthritis underwent injection of one joint of the symmetrical joint pair with $1 \mathrm{mg} / \mathrm{kg}$ (maximum $40 \mathrm{mg}$ ) of TH and injection of the other joint in the pair with $2 \mathrm{mg} / \mathrm{kg}$ (maximum $80 \mathrm{mg}$ ) of TA in a double-blinded fashion. Of the joints injected with $\mathrm{TH}, 89.7 \%$ were in remission at six months, $84.6 \%$ at 12 months, and $76.9 \%$ at 24 months. In this more recent report, the presence of radiographic erosions or IACI in the preceding 12 months were again exclusion criteria, however, ongoing chronic disease was not, lessening any selection bias that may have been present in the 2003 report.

\section{Duration of response}

Additional data has been gathered concerning the duration of response obtained after IACI. In the largest retrospective review of children with JCA treated with IACI, Breit and colleagues reported the experience of 194 children who received 1,439 $\mathrm{TH}$ injections and found a mean duration of improvement of 74 weeks. ${ }^{28}$ Improvement was defined more liberally than in other studies, defined as a reduction in the inflammation score (derived from the presence or absence of six clinical variables) of at least $50 \%$ from the inflammation score prior to treatment with IACI. The duration of response differed significantly between subgroups of JCA: children with early-onset pauciarticular JCA type 1 had the longest duration of improvement at 121 weeks, while children with systemic JCA had the shortest duration of improvement at 36 weeks. Using a more stringent definition of remission (defined as complete disappearance of clinical signs of inflammation, as opposed to the definition of improvement utilized by Breit and colleagues), Lepore and colleagues reported a much shorter duration of remission of 13.9 months in a study of 37 children with oligoarticular JIA involving the knees. ${ }^{25}$ In a 2004 retrospective chart review comparing time to relapse following $\mathrm{TH}$ injection to time to relapse following TA injection in 85 children with all subtypes of JRA who underwent 227 IACIs, Eberhard and colleagues reported a mean time to relapse (defined as presence of an active joint as per the attending rheumatologist) of $10.14 \pm 0.49$ months in the group injected with $\mathrm{TH}$ and a mean time to relapse of $7.75 \pm 0.49$ months in the group injected with TA. ${ }^{29}$ More recently, Marti and colleagues found a longer than previously reported median duration of remission of 23.1 months in a retrospective chart review of 60 children with various onset types of JIA who underwent IACI with either TH or TA. ${ }^{30}$

\section{Prevention of long-term sequelae}

Leg length discrepancy is a well-recognized potential consequence of asymmetrical arthritis involving the lower extremities, and is thought to be due to hyperemia to the growth plates in an inflamed joint. ${ }^{31}$ Given that arthritis is frequently asymmetrical in oligoarthritis/pauciarticular JRA, leg length discrepancy is a particular concern in this condition. Sherry and colleagues demonstrated that early (within two months of diagnosis) and repeated IACI is associated with less leg length discrepancy. ${ }^{17}$ In this retrospective study, a group of 16 children with asymmetric pauciarticular JRA involving the lower extremity who had been managed with early and repeated IACI had no instances of unequal leg lengths, whereas seven out of 14 children from a different center who were not treated with IACI had unequal leg lengths, with a mean $( \pm \mathrm{SD})$ difference between leg lengths of $1.0 \pm 1.4$ centimeters.

Additional cases of resolution of joint deformities with IACI have been reported. In the open label study previously discussed by Padeh and Passwell, improvement in the discordance of leg lengths in seven children with leg length discrepancy prior to treatment with IACI was demonstrated, with the average difference in leg lengths improving from $1.5 \mathrm{~cm}$ to $0.8 \mathrm{~cm}$ over the follow-up period. ${ }^{16}$ Additionally, Padeh and Passwell reported the correction of joint contractures in 55 joints of 42 children, with corrections of contractures at the knees, wrists, elbows, and fingers noted. Further, all 11 children with Baker's cysts in this study experienced complete resolution after IACI to the knee, and two children had correction of trigger fingers with IACI.

\section{Radiographic improvement}

Attempts at radiographic documentation of efficacy of IACI have at times yielded conflicting results. Two studies have used gadolinium enhanced magnetic resonance imaging (MRI) pre- and post-IACI in children with chronic arthritis 
to evaluate response. In the initial study, Eich and colleagues performed MRI of 11 affected knees in eight consecutive children with oligoarticular JCA before and one month after IACI (steroid preparation and dose not given). ${ }^{32}$ Effusion and pannus were present in all knees prior to treatment; effusion resolved in seven knees and pannus in four knees following IACI. Three children had popliteal cysts present prior to IACI; the cysts resolved in two of the children after IACI, but persisted in one child whose cyst had ruptured. One child had apparent replacement of the articular cartilage with enhancing pannus at the lateral and medial femoral condyles before treatment that resolved almost completely one month after IACI. Four hips were also injected and evaluated in two patients (one with polyarticular JCA and one with systemic JCA) in this same report, with less efficacious response. Pannus persisted in three of the four hips injected, and the two hips with evidence of destruction of articular cartilage prior to IACI showed no improvement at one month post-IACI.

In a similar study, Huppertz et al showed better, but not complete, responses to IACI. ${ }^{33}$ Radiographic improvement in the extent of articular inflammation following IACI was demonstrated in a prospective evaluation of 21 consecutive children with chronic arthritis who underwent MRI prior to intra-articular injection of $1 \mathrm{mg} / \mathrm{kg} \mathrm{TH}$ (maximum $60 \mathrm{mg}$ ) and at approximately seven weeks and 13 months after IACI. The MRI appearance of all joints examined was improved both at seven weeks and 13 months post-injection, with completely normal MRI studies in 11 joints at seven weeks but in only two joints at 13 months. Eight joints had residual effusion and eight joints had residual synovial enhancement at seven weeks. At 13 months after injection, six joints had slight effusions, 11 joints had synovial enhancement, and two joints had pannus, however, all joints were noted to be better than before the injection.

Magnetic resonance imaging (MRI) studies in adults with RA have documented less consistent improvements after IACI. In one study, although synovial enhancement and the median volume of synovial effusion was significantly decreased one week after injection with TA, the synovial pannus was not affected significantly, and the synovial volume actually increased in two patients. ${ }^{34}$ In a second study in adults with RA, two out of six subjects had reduction in pannus width and decrease in total synovial fluid volume following IACI to the knee, while the other four subjects had minimal changes in fluid and synovium over the four week follow-up period. ${ }^{35}$ More recently, Boesen and colleagues demonstrated no improvement by either ultrasound or MRI four weeks after intra-articular injection of the wrist with
$40 \mathrm{mg}$ methylprednisolone in 12 patients with wrist disease resistant to DMARD therapy. ${ }^{36}$ It may be possible that the absence of response seen was related to the use of an inferior steroid preparation for intra-articular deposition, however, the systemic nature of the disease may also have contributed to the poor response seen to localized therapy.

\section{Other benefits}

Additional anecdotal benefits of IACI have been reported. In the report by Padeh and Passwell, 60\% of children to were able to discontinue all oral medications following IACI, limiting potential toxicity and inconvenience. ${ }^{16} \mathrm{~A}$ transient remission of systemic manifestations following intra-articular TH injection was reported in a boy with systemic-onset JIA. ${ }^{37}$ Positive effects have also been reported in joints that were not injected in patients that underwent IACI at other sites, including improvement in gait pattern at uninjected joints. ${ }^{19}$ Presumably these more distant effects are secondary to systemic actions of the steroid. Further, although the majority of reports of the use of IACI in the treatment of JIA focus on injections of the knee, IACIs have been shown to be useful in the treatment of arthritis of other joints, including the hip, ${ }^{38-40}$ subtalar joints, ${ }^{40-43}$ wrist, ${ }^{44}$ and temporomandibular joints. ${ }^{45,46}$

\section{Factors affecting outcome Technical aspects}

One of the most important technical factors affecting the success of an IACI is the corticosteroid preparation used, with excellent evidence supporting the use of $\mathrm{TH}$ as the preparation of choice (Table 2). In the 1970s, investigations comparing various steroid preparations were carried out in adults with RA. Bird and colleagues reported a doubleblinded comparison of prednisolone t-butyl acetate, methyl prednisolone acetate, and $\mathrm{TH}$ used to treat adult RA patients with synovitis of the knee and found that $\mathrm{TH}$ injection resulted in significantly greater initial improvement and more durable improvement in joint inflammation as assessed by thermogram than the other steroid preparations. ${ }^{47}$ In the first double-blinded comparison of steroid preparation reported in children, $\mathrm{TH}$ was superior to betamethasone in reducing knee swelling and stiffness in children with oligoarticular disease. ${ }^{22}$ Honkanen and colleagues compared the results of 45 children with various types of JCA injected at the knee with $1.5 \mathrm{mg} / \mathrm{kg}$ methylprednisolone to 34 children injected with $0.7 \mathrm{mg} / \mathrm{kg}$ of TH and found the overall probability of a patient staying in remission was considerably higher in the TH group. ${ }^{26}$ More recently, Zulian and colleagues reported 
Table 2 Summary of features possibly affecting outcome after $I A C I$
I. Technical aspects
A. Steroid preparation used
B. Dose of steroid
C. Radiographic guidance
D. Adequate anesthesia
E. Post-injection care

II. Patient and disease characteristics
A. Disease subtype
B. Specific joint injected
C. Patient sex*
D. Patient age*
E. Disease duration*
F. Higher ESR*
G. \% PMNs in synovial fluid*
H. Higher level synovial fluid macrophage inhibitory factor
I. ANA status*
J. Concomitant medications
K. Initial treatment vs. re-treatment*

Note: *Conflicting data amongst studies.

Abbreviations: ANA, anti-nuclear antibodies; ESR, erythrocyte sedimentation rate; IACl, intra-articular corticosteroid injection; PMNs, polymorphonuclear leukocytes.

better response rates with TH than TA in 85 children with oligoarticular JIA injected with the preparation available for use at the time of treatment. ${ }^{20}$ Response rates at 6,12 , and 24 months were $81.4 \%, 67.1 \%$, and $60 \%$ when TH was used, compared to $53.3 \%, 43.3 \%$, and $33.3 \%$ with TA, respectively. Further, in the double-blinded study comparing TA at twice the dose of TH in children with symmetrical arthritis (one joint of the joint pair injected with TH, the second joint in the pair injected with TA at twice the dose), Zulian and colleagues found that $\mathrm{TH}$ remained superior to TA even when the TA dose was doubled. ${ }^{21}$ In this report, the joint injected with TA relapsed first in $53.8 \%$ of the joints injected, whereas only six (15.4\%) of the joints injected with $\mathrm{TH}$ relapsed first. Eberhard and colleagues reported longer time to relapse with $\mathrm{TH}$ when compared to TA in a retrospective chart review of 227 joints injected, finding a mean time to relapse $( \pm \mathrm{SE})$ of $10.14 \pm 0.49$ months in the TH group versus $7.75 \pm 0.49$ months in the TA group. ${ }^{29}$ Marti and colleagues also confirmed the superiority of TH over TA for IACI of the knees in a retrospective review. ${ }^{30}$ The greater efficacy of TH in intra-articular injections can likely be explained by its lower solubility and slower absorption compared to TA, thus maintaining synovial levels for a longer time and creating lower systemic corticoid levels. ${ }^{48}$

Other than the comparison of TA at twice the dose to $\mathrm{TH}$, no studies have prospectively evaluated different dosing regimens in children. In the study by Allen, dosing of $\mathrm{TH}$ was not specified but ranged from $20-40 \mathrm{mg}$ per knee; a dose-dependent relationship to response was reported, with a higher mean dose in the response group $(1.08 \mathrm{mg} / \mathrm{kg})$ compared to the relapse group $(0.65 \mathrm{mg} / \mathrm{kg}) .^{9}$ In general, the accepted doses used for $\mathrm{TH}$ are $1 \mathrm{mg} / \mathrm{kg}$ for large joints (knees, hips, and shoulders), $0.5 \mathrm{mg} / \mathrm{kg}$ for smaller joints (ankles, wrists, and elbows), 1-2 mg/joint for metacarpophalangeal joints and metatarsophalangeal joints, and 0.6-1 mg/joint for proximal interphalangeal joints. ${ }^{5}$

Undoubtedly, the specific technique and procedures utilized during the administration of an IACI have a large impact on the success of the therapy; however this is a very difficult aspect to assess due to the large variations in technique that occur in individual practices. ${ }^{49}$ In an interesting evaluation performed with adult providers in which radiographic contrast medium was mixed with the steroid preparation and a plain radiograph was taken following the IACI to document the location of the injected material, only 56 of 108 joint injections (52\%) were documented to result in accurate intra-articular placement of the steroid. ${ }^{50}$ Although similar provider-specific practices have not been assessed expressly in pediatric providers, it is conceivable that similar rates of inaccuracy would apply. Radiographic guidance has been shown to improve the accuracy of IACI, particularly in less visually accessible joints, such as the 
subtalar and temporomandiblar joints. In a report of 11 consecutive JCA patients that underwent clinical and MRI evaluation of the tibiotalar and subtalar joints, MRI-guided IACI resulted in at least six months remission in 6 of 9 ankles injected, compared to 1 of 10 ankles which had been previously treated with unguided IACI. ${ }^{43}$ Additionally, a retrospective review of 38 children with all subtypes of JIA who underwent 55 fluoroscopically-guided IACIs of the subtalar joints demonstrated improvement after $89 \%$ of the injections with a mean duration of improvement of 1.2 years. $^{42}$ Adequate relaxation and anesthesia are also essential to obtaining an accurate IACI, ${ }^{5}$ and multiple methods of sedation for younger children, including use of local anesthetics, benzodiazepines, ${ }^{4}$ ketamine and propofol, ${ }^{51}$ nitrous oxide, ${ }^{52}$ and general anesthesia have been employed. In fact, the use of general anesthesia has been associated with a longer duration of IACI-induced remission than other types of anesthesia or no anesthesia in a subgroup analysis of knee IACI in children with JIA. ${ }^{30}$

As with the specific injection procedures, considerable practice variation exists regarding post-IACI care and activity recommendations. Various recommendations that have been suggested include complete bed rest, nonweight bearing, full-time splint use, and return to usual activities. This topic has been the subject of a systematic review, ${ }^{2}$ however, no controlled studies of rest or splints have been pursued in children. In fact, many of the previously discussed studies regarding the use of IACI in JIA do not report what post-IACI care was utilized. In the adult literature, a randomized controlled trial of bed rest versus no bed rest following IACI of the knee in 91 adults with inflammatory arthritis found that the rested group had significant improvement in pain, stiffness, knee circumference and walking time over the nonrested group. ${ }^{53}$ Resting of the wrist post-IACI, however, does not appear to be beneficial. In a randomized controlled trial of rest versus no rest in 117 adults with RA who underwent IACI of the wrist, the relapse rate was higher in the rested group, and there was no difference between the two groups in terms of pain, joint circumference, wrist function, grip strength, or range of motion. ${ }^{54}$

\section{Patient and disease characteristics}

Several of the studies of the efficacy of JIA discussed above included post hoc analyses attempting to identify demographic, clinical, or laboratory features that were associated with response to IACI; the majority of these analyses have yielded conflicting results, likely due to small sample sizes. A single prospective study of 94 patients reported by Ravelli and colleagues used logistic regression to identify predictors of the clinical response to IACI of the knees in children with JIA, and found that children with a higher erythrocyte sedimentation rate (ESR) were more likely to have a sustained response to IACI. ${ }^{24}$ In general, data associating patient and disease characteristics with the outcome of IACI are scare and insufficient to support any definitive conclusions.

Demographic characteristics have not been shown to have a replicable association with IACI outcome. Allen and colleagues found a statistically significant more frequent good response in males with JRA, ${ }^{9}$ however, Breit and colleagues reported a better response to IACI in girls (median duration of effect 78 weeks) than in boys (median duration of effect 54 weeks); ${ }^{28}$ additional studies found no relationship between patient sex and response to IACI. ${ }^{20,23}$ Patient age at disease onset has not been found to be a predictive feature..$^{20,23,25,26}$ Younger patient age at time of treatment was associated with good response in the study by Allen, with a mean age $( \pm \mathrm{SD})$ of $8.75 \pm 4.78$ years in the response group versus $14.39 \pm 4.45$ years in the relapse group; ${ }^{9}$ no association between response and age at time of treatment was identified in other studies. ${ }^{20,26,27}$ No studies have evaluated the effect of race or ethnicity on response to IACI.

The onset type of JIA has been convincingly demonstrated to have an important impact on the duration of efficacy of IACI in children with JCA. In the large retrospective chart review of 1,439 TH injections in 194 children with all subtypes of JCA reported by Breit and colleagues, duration of improvement after IACI was significantly different between arthritis subgroups. ${ }^{28}$ While all subgroups showed some degree of efficacy, early-onset pauciarticular (EOPA) JCA type 1 patients had the longest duration of improvement at 121 weeks, followed by rheumatoid factor (RF) negative polyarticular JCA patients at 105 weeks, then RF-positive polyarticular JCA patients at 63 weeks, then late-onset onset pauciarticular JCA patients at 47 weeks, and, finally, systemic JCA patients with the shortest duration of improvement at 36 weeks. However, these results were not confirmed in the retrospective chart review by Marti and colleagues, who found a longer duration of response in children with enthesitis-related arthritis (ERA), although only four children with ERA were included in the study. ${ }^{30}$ Further, Honkanen and colleagues did not find onset type to be predictive of length of remission after IACI, however, in his group of 79 study subjects, only one child had systemic JCA, making it unlikely that such an association would be found. ${ }^{26}$ 
Duration of disease and initial treatment versus treatment of relapse have both been demonstrated to have associated with IACI outcome in some reports, but not confirmed by others. Lepore and colleagues found that children treated within six months of disease onset were more likely to experience an IACI-induced remission than those patients with more long standing disease. ${ }^{25}$ Both Allen and colleagues and Hertzberger-ten Cate also found a shorter duration of disease to be associated with better response to IACI, ${ }^{9,23}$ however, Zulian and Honkanen found no such relationship. ${ }^{20,26}$ Likewise, the data regarding whether an IACI given as a first injection versus a re-treatment impacts the efficacy of the IACI are conflicting. Zulian and Allen found no difference in response whether the IACI was an initial treatment or re-treatment, ${ }^{9,20}$ yet Breit and colleagues found that efficacy (as determined by duration of improvement) decreased with each subsequent re-injection. ${ }^{28}$

Although the majority of studies of the efficacy of IACI in JIA concern injections to the knees in particular, reports that include injections of other joints suggest that the specific joint injected appears to impact the efficacy of the IACI. Breit and colleagues reported that the duration of improvement following IACI depended on which joint was injected, with the duration of effect for each joint again varying significantly among onset type of JCA. ${ }^{28}$ In patients with EOPA JCA, knees had the longest duration of improvement; in all other types of JCA, hands and feet joints had the longest duration of improvement. Specifically within the EOPA group, knees had the longest median duration of response (120 weeks), followed by hand joints ( $>77$ weeks), then ankles ( 72 weeks), feet ( $>68$ weeks), elbows ( $>67$ weeks), wrists ( $>55$ weeks), shoulders ( $>52$ weeks), and hips ( $>48$ weeks). However, no significant difference in median duration of effect in joints of the upper extremity compared to those of the lower extremity was found. This contrasts to the report by Marti and colleagues, in which injection of joints of the upper extremity had a longer duration of remission. ${ }^{30}$ In the 2003 report by Zulian and colleagues in which either knees or ankles were injected in children with oligoarthritis, ankles showed a significantly worse response than knees at all time points evaluated. ${ }^{20}$

Investigations have been pursued with the goal of identifying laboratory parameters at the time of treatment that predict response to IACI. Of these, only the report by Ravelli and colleagues described above investigated this aim in a prospective manner, using logistic regression to identify higher ESR as the only factor evaluated associated with a sustained clinical response. ${ }^{24}$ The authors suggested that JIA patients who had higher ESR had a synovial inflammatory process that was more sensitive to IACI than children with lower ESR. Patients with a high proportion of polymorphonuclear leukocytes (PMNs) in the synovial fluid were found to have significantly shorter remissions than patients with lower proportions of PMNs in the synovial fluid in the report by Honkanen and colleagues. ${ }^{26}$ Conversely, Padeh and Passwell found no significant differences in the ESR, synovial and peripheral white blood cell counts and percentage of PMNs between the IACI responder and nonresponder groups. ${ }^{16}$

Immunologic and genetic features have also been investigated with regards to possible associations with IACI response. Macrophage migration inhibitory factor (MIF), an immunostimulatory and pro-inflammatory cytokine, has been demonstrated to be functionally relevant in regards to response to IACI, with higher synovial fluid levels of MIF inversely correlated with duration of response to IACI in patients with oligoarticular and systemic-onset JIA $;{ }^{55}$ further, the presence of the MIF- $173^{*} \mathrm{C}$ polymorphism in children with systemic-onset JIA was associated with a significantly shorter duration of response to TH injection (and with other surrogates of poor outcome) than in systemic-onset JIA patients without the allele. ${ }^{56}$ The absence of anti-nuclear antibodies (ANA) was found to be associated with a better response in children with oligoarthritis/EOPA by both Lepore and Breit, ${ }^{25,28}$ leading to speculation that the presence of ANA signifies more immunologically active disease that is less responsive to IACI; other studies found no association with ANA status and response to IACI. ${ }^{9,20,23}$ Further, no difference in the distribution of human leukocyte antigen (HLA)-A, -B, or -DR antigens between IACI responders and nonresponders was found by Allen and colleagues, ${ }^{9}$ although Breit and colleagues found that HLA-B27 negative children responded better to IACI than those children with HLA-B27.28

It is reasonable to assume that the use of concomitant medications would influence the outcome to IACI, unfortunately, the majority of published studies do not account for this variable. However, a recently published retrospective review did analyze this covariate, and, in fact, found concomitant use of methotrexate to be the strongest predictive factor in the study and highly significantly associated with a longer duration of remission to IACI. ${ }^{30}$

\section{Safety}

Early animal studies demonstrating decreased synthesis of collagen and proteoglycans with the development of fissures and cysts leading to destruction of rabbit articular cartilage following IACI of hydrocortisone acetate in a dose-dependent manner initially gave reason to question 
the safety of using IACI as a treatment approach (Table 3). ${ }^{57}$ However, subsequent experiments evaluating the effect of IACI with methylprednisolone on primate cartilage (Macaca irus monkeys) found no change in the joints injected with corticosteroids compared to joints that received control injections. ${ }^{58}$ Since these early animal studies, radiographic studies have not demonstrated deleterious effects of IACI on human cartilage. In the report by Eich and colleagues, MRI and ultrasonography performed in children with JRA prior to IACI and one week and one month post-IACI demonstrated no evidence of destruction of ligaments, avascular necrosis, or other cartilage damage post-IACI. ${ }^{32}$ Further, Huppertz and colleagues confirmed these results, finding no evidence of toxic effects of IACI on cartilage in 21 children with JRA who underwent MRI before and seven weeks after IACI. ${ }^{33}$

Radiographic studies have also demonstrated other, generally clinically insignificant, findings after IACI. In a blinded retrospective review of 39 children with JRA who received 92 IACI, joint calcifications were found to be a potential consequence of IACI, with 20 children exhibiting joint calcifications by plain radiographs. All of the calcifications were incidental findings and were asymptomatic except for one calcium deposit in a 16-year-old girl's knee that had broken into the joint as a loose body, causing pain and locking in the knee and requiring surgical excision. ${ }^{59}$ The location of the calcifications was related to the site of the needle perforation, and the calcifications were more likely to occur periarticularly or in the joint capsule, rather than intraarticularly. Job-Deslandre and Menkes reported the rate of intra-articular calcifications to be $4.9 \%$ in their series of 48 children with JRA or HLA-B27 associated arthritis treated with IACI ${ }^{60}$ In a retrospective review of radiographs of 145 joints of 55 children with chronic arthritis treated with intraarticular TH by Sparling and colleagues, the rate of possible deleterious effects was low, noted in 16 joints of 11 children, including nine joints with periarticular calcifications. ${ }^{61}$ Other possible radiographic effects of IACI reported in this study

Table 3 Adverse events related to $\mathrm{IACl}$ reported in children

I. Peri-articular calcifications

2. Subcutaneous atrophy at injection site

3. Hypopigmentation at injection site

4. "Crystal synovitis"

5. Transient suppression of endogenous cortisol production/exogenous hypercortisolism

6.Avascular necrosis of the femoral head

7. Difficulty maintaining glucose control in diabetic children

Abbreviation: $\mathrm{IACl}$, intra-articular corticosteroid injection. included small patella (two joints), patellar osteochondritis dissecans (one joint), intra-articular tibial bone spur (one joint), avascular necrosis (AVN) of the distal radial epiphysis (two joints), and AVN of the proximal femoral epiphysis (one joint); only the case of femoral AVN was symptomatic and radiographic abnormalities were present prior to the IACI. The authors concluded that the use of IACI was not associated with any significant joint damage, with many of the radiographic findings consequences of chronic arthritis that could also be seen in children who had not received IACI.

The most well-recognized and common adverse effect seen after IACI is that of subcutaneous atrophy with or without hypopigmentation at the injection site. The reported rates of subcutaneous atrophy vary depending on the series, ranging from $0 \%{ }^{26}$ to $10 \%,{ }^{25}$ with the majority of series reporting a rate of subcutaneous atrophy between $1 \%-4 \%$. In an early report of severe cutaneous atrophy at the site of IACI in eight adult patients with RA compared to results obtained after injecting the same corticosteroid preparations into the skin of rabbits, higher potency, concentration, and volume of injected corticosteroid were related to the development of atrophy. ${ }^{62}$ Injection techniques that allowed leakage of the steroid into the subcutaneous tissues and injection of small joints with less extra-articular tissues were also related to the development of atrophy. This knowledge has led some practitioners to use more soluble steroid preparations, such as betamethasone or methylprednisolone, in place of TH when injecting small joints of the hands and feet. This complication appears late, often six months or later after the IACI, ${ }^{28}$ and frequently undergoes spontaneous resolution, ${ }^{16,25,62}$ although persistent atrophy of up to four years duration have been reported. ${ }^{60}$

Potential complications that are inherent to all types of injections and are not particular to IACI have been reported, primarily in adults, and include injection site bleeding, injection site pain, and syncope proximate to the timing of the injection. ${ }^{63}$ These potential complications are readily manageable, and, in fact, are often preventable if proper technique and adequate anesthesia are employed.

An inflammatory reaction characterized by acute increase in pain, swelling and redness occurring in the first 24 hours after an IACI is a rare, but well-documented adverse reaction to IACI. It is likely due to the intra-articular formation of corticosteroid crystals that incite a reactive synovitis, and is thus termed "crystal synovitis." 64 Also referred to as "steroid flare," intra- and extra-cellular rod-shaped crystals have been demonstrated in the synovial fluid post-IACI by compensated polarized microscopy, and increased synovial 
white blood cell counts (predominantly PMNs) post-IACI are well-documented. ${ }^{65}$ Post-IACI inflammatory flare is reported in approximately $1 \%-2 \%$ of adult patients, ${ }^{66}$ and is felt to be more common with earlier steroid preparations, such as hydrocortisone acetate, but has also been reported with TH. Crystal synovitis has also been reported in children, ${ }^{16,23}$ and is self-limited with resolution in three to five days with supportive care, including NSAIDs and rest.

Intra-articularly administered $\mathrm{TH}$ has been documented to be detectable in the sera of adults for up to three weeks post-IACI 67 and intra-articularly administered TA has been demonstrated in the plasma and urine of children 4-5 months post-IACI ${ }^{68}$ prompting concern for the potential of systemic adverse effects. In fact, symptomatic suppression of the hypothalamic-pituitary-adrenal axis in an adult with RA following long-term use of IACI every eight weeks for an eight year time period has been reported. ${ }^{69}$ Transient suppression of endogenous cortisol production following single IACI treatment was documented by Huppertz and Pfuller in 22 children with chronic arthritis, all of whom had morning cortisol levels that were depressed below the lower limit of normal by salivary samples obtained shortly after IACI. ${ }^{70}$ All of the cortisol levels returned to normal within seven weeks of the IACI, and in the 11 children for whom data were available, the median time to return to normal cortisol levels was 16 days. No adverse effects related to steroid withdrawal or excess were reported. Although no symptoms related to hypercortisolism were reported in this series, the use of multiple $(>10)$ IACI has been associated with Cushingoid features in children with polyarticular disease due to increase systemic steroid absorption, ${ }^{71}$ and Kumar and colleagues reported the case of a 9-year-old girl who developed fullness and flushing of the face, a dorsocervical hump, striae and weight gain after multiple IACI (total dose $120 \mathrm{mg}$ TA) lasting for five months. ${ }^{68}$ Systemic effects of hypercortisolism have also been reported after a single IACI, including facial flushing, increased appetite, mood changes, weight gain, striae, and easy bruisability. ${ }^{30,68}$ It is likely that the effects of IACI on adrenal suppression and cortisol excess are decreased when $\mathrm{TH}$ is the steroid preparation used instead of TA. Suppression of endogenous cortisol suppression at four weeks post-IACI was least marked with $\mathrm{TH}$ in comparison to other corticosteroid preparations, ${ }^{47}$ likely due to its increased intra-articular residence (and thus decreased systemic absorption). Further, in a retrospective review of 195 children who received IACI with either TA or $\mathrm{TH}, 5 \%$ of children who received TA had visibly prominent Cushing's syndrome, while no children who were injected with TH had Cushingoid features, even when multiple joints were injected. ${ }^{72}$

Other potential systemic effects of intra-articularly administered corticosteroids should be considered. Children with type 1 diabetes mellitus may potentially experience transient difficulty maintaining blood glucose control if multiple IACIs are administered. ${ }^{73}$ Allergic reactions, ranging from mild hives to anaphylactic shock, have been reported in adults immediately after treatment with IACI, with skin prick and intradermal testing confirmatory of allergy to the corticosteroid preparation and not to co-administered vehicles or anesthetics; ${ }^{74,75}$ no such allergic reactions have been reported to date in children. Although transient (less than 1-2 weeks) suppressive effects on leg growth measured by knemometry have been anecdotally reported, ${ }^{76}$ no cases of growth suppression due to IACI therapy have been reported. In fact, in the 1995 report by Huppertz, after one year of follow-up post-knee IACI, there was no effect on statural growth. ${ }^{33}$

Intra-articular infection perhaps remains one of the most worrisome theoretical complications of IACI, but to date, there have been no cases of septic arthritis reported in children post-IACI. The reported risk of septic arthritis post-IACI in adults is $0.002 \%$ (out of 100,000 procedures), ${ }^{14}$ but nonetheless, strict aseptic procedure must be a priority to prevent this serious complication. Anecdotally, a case of a septic ankle developing 48 hours after an IACI to the knee in a child with an intercurrent respiratory infection has been reported. ${ }^{77}$

Mechanical consequences of IACI have also been reported, most commonly after hip injections. AVN of the femoral head following IACI was reported in two children in a series of 48 children with JRA treated with IACI for coxitis. ${ }^{39}$ Both children had long-standing disease (systemic JRA and RF-negative polyarthritis) requiring systemic corticosteroid therapy and repeated IACI who developed AVN 44 and 21 months after the last hip injection. The first child also developed necrosis of the humeral head which was not injected, so it is likely that the AVN was due to chronic synovitis or systemic steroid use rather than the IACI, as AVN of the femoral head is a well-recognized complication of arthritis of the hip in the absence of IACI treatment. Breit and colleagues also reported a single episode of AVN of the hip three months post-IACI in a child with systemic JCA and pre-existing osteoarthrosis. ${ }^{28}$ This child was unable to walk prior to the IACI, and the authors suggested that it was the return of her ability to walk with increased physical activity post-IACI that lead to the progressive joint destruction 
following the IACI. In a different series of intra-articular hip injections in children with JCA, no cases of AVN were reported in the 37 hips with at least 12 months of follow-up or in the 20 hips with at least 24 months of follow-up. ${ }^{38}$ An interesting anecdotal case of bilateral shoulder subluxations in a 14-year-old girl with RF-positive polyarticular JCA that occurred 2 days after bilateral shoulder IACI has been reported. ${ }^{28}$ This child also had long-standing arthritis with radiographic changes noted in the shoulders prior to receiving IACI; the authors speculated that the reduction of joint inflammation with decreased synovial thickening and intra-articular effusion lead to joint instability and the subluxation.

Finally, although it has not been studied in a controlled fashion, the use of repeated injections to an individual joint appears to be safe and has not been associated with adverse outcomes. ${ }^{6}$ Repeated IACI are used by some in clinical practice, and in the report by Sherry and colleagues comparing leg length discrepancies in children treated with IACI to those who did not receive IACI, almost all children in the IACI group received subsequent injections; the maximum time any individual joint was injected was 4 . No adverse events related to multiple IACI were reported. ${ }^{17}$ In a small report of three children with oligoarticular JCA who required repeated IACI (ranging from 11-14 IACI per child), MRI performed 6-13 years after treatment revealed no deleterious effects. ${ }^{78}$ Occasional reports of clinical and radiographic changes similar to those seen in Charcot-like (neuropathic) arthropathies have been reported in adults after repeated IACI relieved pain and facilitated overuse of a joint, leading to trauma to the joint: ${ }^{79}$ this phenomenon has not been reported in children.

\section{Conclusions}

IACI is a safe and effective treatment option in the management of JIA, particularly in the management of oligoarthritis. It has been well-demonstrated that use of IACI can control disease activity and induce resolution of synovitis, decrease the presence of joint and limb deformities, improve function, provide pain relief, and serve as an adjunct to minimize more toxic treatments. Various technical aspects, patient characteristics, and disease features impact the efficacy of IACI, although conclusive data that elucidates these factors are scarce. Extensive data regarding the incidence of adverse effects related to IACI support the assertion that IACI is a safe treatment option, with the majority of reported adverse effects being of minimal clinical significance. Definitive studies are needed to identify factors associated with response to IACI so that this treatment modality may be utilized to optimum effectiveness.

\section{Acknowledgments}

The author would like to thank Dr Marilynn Punaro for her thoughtful review of this manuscript. The author reports no conflicts of interest in this work. This publication was supported by Grant Number KL2RR024983, titled, "North and Central Texas Clinical and Translational Science Initiative" (Milton Packer, MD, PI) from the National Center for Research Resources (NCRR), a component of the National Institutes of Health (NIH), and NIH Roadmap for Medical Research, and its contents are solely the responsibility of the author and do not necessarily represent the official views of the NCRR or NIH. Information on NCRR is available at http://www.ncrr.nih.gov/. Information on Re-engineering the Clinical Research Enterprise can be obtained from http://nihroadmap.nih.gov/clinicalresearch/ overview-translational.asp.

\section{References}

1. Petty RE, Southwood R, Manners P, et al. International League of Associations for Rheumatology classification of juvenile idiopathic arthritis: second revision, Edmonton, 2001. J Rheumatol. 2004;31(2):390-392.

2. Wallen M, Gillies D. Intra-articular steroids and splints/rest for children with juvenile idiopathic arthritis and adults with rheumatoid arthritis. Cochrane Database Syst Rev. 2006;1:CD002824.

3. Dent PB, Walker N. Intra-articular corticosteroids in the treatment of juvenile rheumatoid arthritis. Curr Opin Rheumatol. 1998;10(5): 475-480.

4. See Y. Intra-synovial corticosteroid injections in juvenile chronic arthritis - a review. Ann Acad Med Singapore. 1998;27(1):105-111.

5. Cleary AG, Murphy HD, Davidson JE. Intra-articular corticosteroid injections in juvenile idiopathic arthritis. Arch Dis Child. 2003;88(3): 192-196.

6. Hashkes PJ, Laxer RM. Medical treatment of juvenile idiopathic arthritis. JAMA. 2005;294(13):1671-1684.

7. Hollander JL, Brown EM Jr, Jessar RA, et al. Hydrocortisone and cortisone injected into arthritis joints; comparative effects of and use of hydrocortisone as a local antiarthritic agent. JAMA. 1951;147(17): 1629-1635.

8. Bernstein BH, Thompson DM, Singsen BH. Medical therapy of juvenile rheumatoid arthritis. In: Miller III, JJ, editor. Juvenile Rheumatoid Arthritis. Littleton, MA, PSG Publishing Co; 1979. p. 197.

9. Allen RC, Gross, KR, Laxer RM, Malleson PN, Beauchamp RD, Petty RE. Intraarticular triamcinolone hexacetonide in the management of chronic arthritis in children. Arthritis Rheum. 1986(8);29: 997-1001.

10. Brunner HI, Kim KN, Ballinger SH, et al. Current medication choices in juvenile rheumatoid arthritis II-update of a survey performed in 1993. J Clin Rheumatol. 2001;7(5):295-300.

11. Cron RQ, Sharma S, Sherry DD. Current treatment by United States and Canadian pediatric rheumatologist. J Rheumatol. 1999;26(9): 2036-2038.

12. Beukelman T, Guevara JP, Albert DA, et al. Variation in the initial treatment of knee monoarthritis in juvenile idiopathic arthritis: a survey of pediatric rheumatologists in the United States and Canada. J Rheumatol. 2007;34(9):1918-1924. 
13. Barnes PJ. Anti-inflammatory actions of glucocorticoids: molecular mechanisms. Clin Sci. 1998;94(6):557-572.

14. Gray RG, Tenebaum J, Gottleib NL. Local corticosteroid injection treatment in rheumatic disorders. Semin Arthritis Rheum. 1981;10(4): 231-254.

15. Alex P, Szodoray $P$, Arthur E, et al. Influence of intraarticular corticosteroid administration on serum cytokines in rheumatoid arthritis. Clin Rheumatol. 2007;26(5):845-848.

16. Padeh S, Passwell JH. Intraarticular corticosteroid injection in the management of children with chronic arthritis. Arthritis Rheum. 1998;41(7):1210-1214.

17. Sherry DD, Stein LD, Reed AM, Schanberg LE, Kredich DW. Prevention of leg length discrepancy in young children with pauciarticualr juvenile rheumatoid arthritis by treatment with intraarticular steroids. Arthritis Rheum. 1999;42(11):2330-2334.

18. Pelkonen PM. Juvenile arthritis with oligoarticular onset. Ballieres Clin Rheumatol. 1998;12(2):273-286.

19. Brostrom E, Hagelberg S, Haglund-Akerlind Y. Effect of joint injections in children with juvenile idiopathic arthritis: evaluation by $3 \mathrm{D}$-gait analysis. Acta Paediatr. 2004;93(7):906-910.

20. Zulian F, Martini G, Gobber D, Agosto C, Gigante C, Zachello F. Comparison of intra-articular triamcinolone acetonide in oligoartiuclar juvenile idiopathic arthritis. Rheumatology (Oxford). 2003;42(10):1254-1259.

21. Zulian F, Martini G, Gobber G, Plebani M, Zachello F, Manners P. Triamcinolone acetonide and hexacetonide intra-articular treatment of symmetrical joints in juvenile idiopathic arthritis: a double-blind trial. Rheumatology (Oxford). 2004;43(10):1288-1291.

22. Balogh Z, Ruzsonyi E. Triamcinolone hexacetonide versus betamethasone: a double-blind comparative study of the long-term effects of intra-articular steroids in patients with juvenile chronic arthritis. Scand J Rheumatol. 1987;67(suppl):80-82.

23. Hertzberger-ten Cate R, de Vries-van der Vlugt BCM, van SuijlekomSmit LWA, Cats A. Intra-articular steroids in pauciarticular juvenile chronic arthritis, type 1. Eur J Pediatr. 1991;150(3):170-172.

24. Ravelli A, Manzoni SM, Viola S, Pistorio A, Ruperto N, Martini A. Factors affecting the efficacy of intraarticular corticosterid injections of knees in juvenile idiopathic arthritis. J Rheumatol. 2001;28(9):2100-2102.

25. Lepore L, Del Santo M, Malorgio C, et al. Treatment of juvenile idiopathic arthritis with intra-articular triamcinolone hexacetonide: Evaluation of clinical effectiveness correlated with circulating ANA and $\mathrm{T} \gamma / \delta+$ and B CD5+ lymphocyte populations of synovial fluid. Clin Exp Rheumatol. 2002;20(5):719-722.

26. Honkanen VEA, Rautonen JK, Pelkonen PM. Intra-articular glucocorticoids in early juvenile chronic arthritis. Acta Pediatr. 1993;82(12):1072-1074.

27. Earley A, Cuttica RJ, McCullough C, Ansell BM. Triamcinolone into the knee joint in juvenile chronic arthritis. Clin Exp Rheumatol. 1988;6(2):153-155.

28. Breit W, Frosch M, Meyer U, et al. A subgroup-specific evaluation of the efficacy of intraarticular triamcinolone in juvenile chronic arthritis. J Rheumatol. 2000;27(11):2696-2702.

29. Eberhard BA, Sison MC, Gottlieb BS, Ilowite NT. Comparison of the intraarticular effectiveness of triamcinolone hexacetonide and triamcinolone acetonide in treatment of juvenile rheumatoid arthritis. $J$ Rheumatol. 2004;31(12):2507-2512.

30. Marti P, Molinari L, Bolt IB, et al. Factors influencing the efficacy of intra-articular steroid injections in patients with juvenile idiopathic arthritis. Eur J Pediatr. 2008;167(4):425-430.

31. Simon S, Whiffen J, Shapiro F. Leg length discrepancy in monarticular and pauciarticular juvenile rheumatoid arthritis. J Bone Joint Surg Am. 1981;63A:209-215.

32. Eich GF, Halle F, Hodler J, et al. Juvenile chronic arthritis: imaging of the knees and hips before and after intraarticular steroid injection. Pediatr Radiol. 1994;24(8):558-563.

33. Huppertz H, Tschammler A, Horwitz AE, Schwab KO. Intraarticular corticosteroids for chronic arthritis in children: efficacy and effects on cartilage and growth. J Pediatr. 1995;127(2):317-321.
34. Creamer P, Keen M, Zananiri F, et al. Quantitative magnetic resonance imaging of the knee: a method of measuring response to intra-articular treatments. Ann Rheum Dis. 1997;56(6):378-381.

35. Leitch R, Walker SE, Hillard AE. The rheumatoid knee before and after arthrocentesis and prednisolone injection: evaluation by Gd-enhanced MRI. Clin Rheumatol. 1996;15(4):358-366.

36. Boesen M, Boesen L, Jensen KE, et al. Clinical outcome and imaging changes after intraarticular (IA) application of etanercept or methylprednisolone in rheumatoid arthritis: magnetic resonance imaging and ultrasound-doppler show no effect of IA injections in the wrist after 4 weeks. J Rheumatol. 2008;35(4):584-591.

37. Magni Manzoni S, Viola S, Beduschi L, Martini A, Ravelli A. Transient remission of systemic symptoms following intraarticular triamcinolone hexacetonide injection in a boy with systemic onset juvenile idiopathic arthritis. Clin Exp Rheumatol. 2002;20(5):735.

38. Boehnke M, Behrend R, Dietz G, Kuster RM. Intraarticular hip treatment with triamcinolone hexacetonide in juvenile chronic arthritis. Acta Univ Carol [Med] (Praha). 1994;40(1-4):123-126.

39. Neidel J, Boehnke M, Kuster RM. The efficacy and safety of intraarticular corticosteroid therapy for coxitis in juvenile rheumatoid arthritis. Arthritis Rheum. 2002;46(6):1620-1628.

40. Tynjala P, Honkanen V, Lahdenne P. Intra-articular steroids in radiologically confirmed tarsal and hip synovitis of juvenile idiopathic arthritis. Clin Exp Rheumatol. 2004;22(5):643-648.

41. Cahill AM, Cho SS, Baskin KM, et al. Benefit of fluoroscopically guided intraarticular, long-acting corticosteroid injection for subtalar arthritis in juvenile idiopathic arthritis. Pediatr Radiol. 2007;37(6):544-548.

42. Beukelman T, Arabashi B, Cahill AM, et al. Benefit of intraarticular corticosteroid injection under fluoroscopic guidance for subtalar arthritis in juvenile idiopathic arthritis. J Rheumatol. 2006;33(11):2330-2336.

43. Remedios D, Martin K, Kaplan G, et al. Juvenile chronic arthritis: diagnosis and management of tibio-talar and sub-talar disease. $\mathrm{Br} \mathrm{J}$ Rheumatol. 1997;36(11):1214-1217.

44. Evans DM, Ansell BM, Hall MA. The wrist in juvenile arthritis. J Hand Surg (Br). 1991;16(3):293-304.

45. Arabshahi B, Cron RQ. Temporomandibular joint arthritis in juvenile idiopathic arthritis: the forgotten joint. Curr Opin Rheumatol. 2006;18(5):490-495.

46. Arabshahi B, Dewitt EM, Cahill AM, et al. Utility of corticosteroid injection for temporomandibular arthritis in children with juvenile idiopathic arthritis. Arthritis Rheum. 2005;52(11):3563-3569.

47. Bird HA, Ring EFJ, Bacon PA. A thermographic and clinical comparison of three intra-articular steroid preparations in rheumatoid arthritis. Ann Rheum Dis. 1979;38(1):36-39.

48. Derendorf H, Mollman H, Gruner A, et al. Pharmacokinetics and pharmacodynamics of glucocorticoid suspensions after intra-articular administration. Clin Pharmacol Ther. 1986;39(3):313-317.

49. Haslock I, Macfarlane D, Speed C. Intra-articular and soft tissue injections: a survey of current practice. Br J Rheumatol. 1995;34(5): 449-452.

50. Jones A, Regan M, Ledingham J, et al. Importance of placement of intra-articular steroid injections. BMJ. 1993;307(6915):1329-1330.

51. Zulian F, Agosto C, Benini F, et al. Why cry? A simple effective sedation for intraarticular steroid therapy in juvenile chronic arthritis [abstract]. Arthritis Rheum. 1998;41:S46.

52. Cleary AG, Ramanan AV, Baildam E, et al. Nitrous oxide analgesia during intra-articular injection for juvenile idiopathic arthritis. Arch Dis Child. 2002;86(6):416-418.

53. Chakravarty K, Pharoah PD, Scott DG. A randomized controlled study of post-injection rest following intra-articular steroid therapy for knee synovitis. Br J Rheumatol. 1994;33(5):464-468.

54. Weitoft T, Ronnblom L. Randomised controlled study of postinjection immobilization after intra-articular glucocorticoid treatment for wrist synovitis. Ann Rheum Dis. 2003;62(10):1013-1015.

55. Meazza C, Travaglino P, Pignatti P, et al. Macrophage migratory inhibitory factor in patients with juvenile idiopathic arthritis. Arthritis Rheum. 2002;46(1):232-237. 
56. DeBenedetti F, Meazza C, Vivarelli M, et al. Functional and prognostic relevance of the -173 polymorphism of the macrophage migration inhibitory factor gene in systemic-onset juvenile idiopathic arthritis. Arthritis Rheum. 2003;48(5):1398-1407.

57. Behrens F, Shepard N, Mitchell N. Alteration of rabbit articular cartilage by intra-articular injections of glucocorticoids. J Bone Joint Surg Am. 1975;57(1):70-76.

58. Gibson T, Burry HC, Poswillo D, Glass J. Effect of intra-articular corticosteroid injections on primate cartilage. Ann Rheum Dis. 1976;36(1):74-79.

59. Gilsanz V, Bernstein BH. Joint calcification following intra-articular corticosteroid therapy. Radiology. 1984;151(3):647-649.

60. Job-Deslandre C, Menkes CJ. Complications of intra-articular injections of triamcinolone hexacetonide in chronic arthritis in children. Clin Exp Rheumatol. 1990;8(4):413-416.

61. Sparling M, Malleson P, Wood, B, Petty R. Radiographic followup of joints injected with triamcinolone hexacetonide for the management of childhood arthritis. Arthritis Rheum. 1990;33(6):821-826.

62. Cassidy JT, Bole GG. Cutaneous atrophy secondary to intra-articular corticosteroid administration. Ann Intern Med. 1966;65(5):1008-1018.

63. Kumar N, Newman RJ. Complications of intra- and peri-articular steroid injections. Br J Gen Pract. 1999;49(6):465-466.

64. McCarty DJ Jr, Hogan JM. Inflammatory reaction after intrasynovial injection of microcrystalline adenocorticosteroid esters. Arthritis Rheum. 1964;7:359-367.

65. Berger RG, Yount WJ. Immediate "steroid flare" from intraarticular triamcinolone hexacetonide injection: case report and review of the literature. Arthritis Rheum. 1990;33(8):1284-1286.

66. Hollander JL. Intrasynovial corticosteroid therapy in arthritis. Md Med J. 1970;19(3):62-66

67. Derendorf H, Mollmann H, Gruner A, et al. Pharmacokinetics and pharmacodynamics of glucocorticoid suspensions after intra-articular administration. Clin Pharmacol Ther. 1986;39(3):313-317.

68. Kumar S, Singh RJ, Reed AM, Lteif AN. Cushing's syndrome after intra-articular and intradermal administration of triamcinolone acetonide in three pediatric patients. Pediatrics. 2004;113(6):1820-1824.
69. O’Sullivan MM, Rumfield WR, Jones MK, Williams BD. Cushing's syndrome with suppression of the hypothalamic-pituitary-adrenal axis after intra-articular steroid injections. Ann Rheum Dis. 1985;44(8): 561-563.

70. Huppertz H, Pfuller H. Transient suppression of endogenous cortisol production after intraarticular steroid therapy for chronic arthritis in children. J Rheumatol. 1997;24(9):1833-1837.

71. Wallace CA. On beyond methotrexate treatment of severe juvenile rheumatoid arthritis. Clin Exp Rheumatol. 1999;17(4):499-504.

72. Gondwe JS, Davidson JE, Deeley S, Sills J, Cleary AG. Secondary Cushing's syndrome in children with juvenile idiopathic arthritis following intra-articular triamcinolone acetonide administration. Rheumatology (Oxford). 2005;44(11):1457-1458.

73. Murray KJ, Lovell DJ. Advanced therapy for juvenile arthritis. Best Pract Res Clin Rheumatol. 2002;16(3):361-378.

74. Mace S, Vadas P, Pruzanski W. Anaphylactic shock induced by intraarticular injection of methylprednisolone acetate. J Rheumatol. 1997;24(6):1191-1194.

75. Karsh J, Yang WH. An anaphylactic reaction to intra-articular triamcinolone: a case report and review of the literature. Ann Allergy Asthma Immunol. 2003;90(2):254-258.

76. Heuck C, Wolthers OD, Herlin T. Growth-suppressive effect of intra-articular glucocorticoids detected by knemometry. Horm Res. 1999;52(2):95-96.

77. Shore A, Rush PJ. Possible danger of intra-articular steroid injection in children with respiratory tract infections. $\mathrm{Br} J$ Rheumatol. 1987;26(1):73

78. Magnusson B, Jenner G, Andersson U, Hagelberg S. Do frequent corticosteroid injections in the knee cause cartilage damage in juvenile chronic arthritis? 6-13 years follow up with MRI [abstract]. J Rheumatol. 2000;27(suppl 58):95.

79. Alacron Segovia D, Wald LE. Charcot-like arthropathy in RA: consequence of overuse of a joint repeatedly injected with hydrocortisone. JAMA. 1965;193:1052-1054.
Open Access Rheumatology Research and Reviews

\section{Publish your work in this journal}

Open Access Rheumatology Research and Reviews is an international, peer-reviewed, open access journal, publishing all aspects of clinical and experimental rheumatology in the clinic and laboratory including the following topics: Pathology, pathophysiology of rheumatological diseases; Investigation, treatment and management of rheumatological

\section{Dovepress}

diseases; Clinical trials and novel pharmacological approaches for the treatment of rheumatological disorders. The manuscript management system is completely online and includes a very quick and fair peerreview system, which is all easy to use. Visit http://www.dovepress.com/ testimonials.php to read real quotes from published authors. 